\title{
Servant Leadership and Follower Voice: The Roles of Follower Felt Responsibility for Constructive Change and Avoidance-Approach Motivation
}

\author{
Ghulam Ali Arain, Ph.D \\ Associate Professor, College of Business \& Economics, (CBE) \\ United Arab Emirates University, Al-Ain, UAE. \\ drghulamaliarain@gmail.com
}

Imran Hameed, Ph.D

Associate Professor, Lahore School of Economics

Lahore, Pakistan

Email: im_hameed@hotmail.com

\author{
Jonathan R. Crawshaw, Ph.D (Corresponding Author) \\ Senior Lecturer, Work and Organisational Psychology Department, \\ Aston Business School, Aston University, B4 7ET. \\ Email: j.r.crawshaw2@aston.ac.uk
}

The data that support the findings of this study are available on request from the corresponding author, Dr. Jonathan R. Crawshaw. The data are not publicly available due to their containing information that could compromise the privacy of research participants. 


\begin{abstract}
Our study contributes to research exploring the differential antecedents of employee promotive and prohibitive voice. We first examined the mediating role of employee felt responsibility for constructive change (FRCC) in the positive relationship between servant leadership and their prohibitive and promotive voice. We then tested the differential moderating effects of employee dispositional avoidance-approach orientation, where the indirect effect of servant leadership on prohibitive voice is weakened for the high avoidance-motivated, and the indirect effect of servant leadership on promotive voice is weakened for the high approach-motivated. To test our hypotheses, multi-source data were collected from 231 supervisor-supervisee dyads working in a range of companies and sectors in the Kingdom of Saudi Arabia. As predicted, employee FRCC mediates the positive relationship between servant leadership and prohibitive voice and these indirect effects are significantly weaker for the high avoidance-motivated. We did not observe the predicted weakening effects of high approach-motivation on the indirect relationship between servant leadership and promotive voice. It seems servant leaders may be less influential for those avoidance-motivated individuals already predisposed to enact prohibitive forms of voice, such as voicing concerns about harmful organisational processes and practices. Implications for social exchange and role theories, and managerial practice, are discussed.
\end{abstract}

Keywords: Servant leadership; felt responsibility for constructive change; voice; avoidanceapproach motivation. 


\section{INTRODUCTION}

Voice refers to the discretionary and constructive upward communication of feedback and new ideas by employees to management. While early work treats voice as a unidimensional construct (Van Dyne, Cummings, \& Parks, 1995), recent studies differentiate its prohibitive and promotive forms (Kakkar, Tangirala, Srivastava, \& Kamdar, 2016). Prohibitive voice refers to employee feedback that highlights current organisational or operational failings, while promotive voice refers to their suggestions of new ideas for improving performance (Li, Liao, Tangirala, \& Firth, 2017). The importance of voice, in both its forms, is well established. For organizations, it is a key source of learning and innovation, better enabling them to change and survive; it's absence a potential source of organizational failure (Graham, 2002; Perlow \& Williams, 2003; Greenberg \& Edwards, 2009; Milliman, Czaplewski \& Ferguson, 2003). For employees, voice communicates their work engagement, loyalty and creativity, potentially improving their future job security, promotion opportunities, and career progression (Llopis, 2012).

Publicly voicing one's thoughts and opinions is not without risk, however. Thus, encouraging employees to engage with change and freely raise their concerns and ideas is not straight forward (Chamberlin et al., 2017; Liang, Farh \& Farh, 2012; Rehg, Miceli, Near \& Van Scotter, 2008). Indeed, past research on employees felt responsibility for constructive change (FRCC), where FRCC is defined as an individual's, "belief that he or she is personally obligated to bring about constructive change" (Morrison \& Phelps, 1999, p. 407), suggests FRCC may be an essential psychological state for employee promotive and prohibitive voice (e.g., Chamberlin et al., 2017; Fuller, Marler\& Hester, 2006). To date, however, few studies have explored the antecedents and boundary conditions of FRCC, thus limiting our understanding of FRCC and its 
role in explaining employee voice, in both its promotive and prohibitive forms. We contribute to this body of knowledge in two important ways.

First, we introduce servant leadership as a new antecedent of employees' FRCC and promotive/prohibitive voice. Servant leaders are distinctive from other follower-focussed leaders (Chiniara \& Bentein, 2016), emphasizing a line manager's one-to-one communications with their employees, providing them with the skills, responsibility and motivation to perform (Liden, Wayne, Liao, \& Meuser, 2014: Liden, Wayne, Zhao, \& Henderson, 2008; van Dierendonck, 2011). Drawing on social exchange theory (Blau, 1964), servant leaders engender their followers' work engagement and intrinsic motivation, by focussing on serving their particular interests (Fuller et al., 2006). We posit, therefore, that followers who view their line manager as a servant leader are more likely to develop a FRCC and, in turn, engage in prosocial promotive and prohibitive voice (Chamberlin et al., 2017).

Second, we examine whether these positive effects of servant leadership for employee FRCC and promotive and prohibitive voice will be felt equally by all individuals, drawing on recent research into the roles of dispositional avoidance-approach motivation on voice (e.g., Ferris et al., 2013, Ferris et al., 2011). Avoidance-approach motivations are broad mental models for personal goal pursuit, where the approach-orientated are predisposed to seek improvement in their own work circumstances by proactively seeking out opportunities to exhibit their skills, and the avoidance-orientated by closely monitoring and avoiding threats (Elliot \& Harackiewicz, 1996). Drawing on role theory (Katz \& Kahn, 1978), and recent research by Kakkar et al. (2016) and Lin \& Johnson (2015), we argue that the predisposition of avoidance orientated individuals to be fearful of threats in the environment (Morrison \& Rothman, 2009) will make salient more prevention-orientated prohibitive voice behaviours. Thus, we posit that the indirect effect of 
servant leadership on employee prohibitive voice, via their FRCC, will be significantly weaker for the already prohibitive voice predisposed avoidance motivated employee. Conversely, and again drawing on Kakkar et al. (2016) and Lin \& Johnson (2015), we argue that the predisposition of approach motivated individuals to proactively seek ideal future states (Grant \& Ashford, 2008) makes salient the more proactive-orientated promotive voice behaviour. Thus, we posit that the indirect effect of servant leadership on employee promotive voice, via their FRCC, will be significantly weaker for the already promotive voice predisposed approach motivated employee.

We propose a number of important contributions. To the best of our knowledge, we provide the first empirical testing of a new moderated-mediation model where, employee FRCC mediates the relationship between servant leadership and their promotive and prohibitive voice and that the indirect relationship between servant leadership and employee prohibitive voice is weaker for the avoidance-motivated, and the indirect relationship between servant leadership and employee promotive voice is weaker for the approach-motivated. This extends recent voice research that explores the differential antecedents of promotive and prohibitive voice (Chamberlin et al., 2017), including the differential effects of follower approach-avoidance motivations for their promotive and prohibitive voice respectively. In turn, by bringing together social exchange theory (Blau, 1964) and role theory (Katz \& Kahn, 1978), we also provide the servant leadership and voice literatures with a new theoretical framework for understanding why, when and how employees engage in either promotive and prohibitive voice.

Our research delivers important practical benefits also. We contribute to the literature extolling the virtues of servant leadership (van Dierendonck, 2011), compelling organizations to consider recruiting and developing 'servant' leaders if they wish to promote a workforce that is 
committed to change, and is willing to freely voice their opinions and ideas on current and future practice. Our research also advises managers how key individual dispositional differences namely avoidance-approach motivation - may nullify and/or heighten these effects, potentially also informing key resourcing decisions.

\section{THEORETICAL FRAMEWORK AND HYPOTHESES}

Early work tended to define voice as an employee's self-oriented reaction to dissatisfying work conditions (Hirschman, 1970). As the literature developed, however, employee voice was defined more in terms of their other-oriented discretionary behaviour focused on improving organizational effectiveness (LePine \& Van Dyne, 1998; Van Dyne et al., 1995). These studies demonstrated, theoretically and empirically, that voice is distinct, not only from other in-role behaviours, but also from other forms of citizenship, such as helping others (Morrison, 2014). Specifically, voice is seen as a particularly high-risk prosocial behaviour as it focuses on employees challenging co-worker, manager, team, and organisational norms, attitudes and behaviours, thus leaving them open to potential criticism, ridicule, and accusations of disloyalty (Van Dyne \& LePine, 1998; Wei et al., 2015).

More recently, scholars further categorised voice into its promotive and prohibitive forms (Liang et al., 2012). Promotive voice refers to employee ideas and suggestions for enhancing organizational effectiveness, and is principally focused on their realization of new ideas (e.g., Liang et al., 2012). Prohibitive voice, on the other hand, refers to employee feedback on organisational norms, practices, attitudes or behaviours that are perceived as harmful, and is focused on the prevention of these harmful issues (Liang et al., 2012). 
While both forms of voice may be considered risky, as they both require employees to challenge the status quo, research is fairly consistent in suggesting that prohibitive voice is riskier as it tends to be more critical and challenging in nature (Chamberlin et al., 2017). Reporting health and safety violations, poor customer service practices, and product/service quality deficiencies, and highlighting the needs for improvement in these areas, are all examples of prohibitive voice. Importantly, raising issues such as these has the potential to create disharmony and conflict between team members, as these actions highlight the potential serious failings of others (Liang et al., 2012; Rehg et al., 2008). This distinction between promotive and prohibitive voice makes salient research that explores how, when and why individuals engage in these different forms of voice. Thus, while early studies confirm a number of potential leadership, attitudinal and dispositional antecedents of a unidimensional - largely promotive voice (e.g., Kong, Huang, Liu, \& Zhao, 2016; Hu, Zhang, \& Wang, 2015; Bai, Lin, \& Liu, 2017), Chamberlin et al. (2017) demand much more research - such as ours - examining the potential differential voice antecedents for promotive and prohibitive forms.

\section{Servant Leadership and Employee Promotive and Prohibitive Voice}

Servant leadership emphasizes line manager one-on-one communications with followers in order to understand their unique needs, goals and qualities, and help them to reach their full potential (Liden et al., 2014; Liden et al., 2008). The employee-focused and moral dimensions of servant leadership raise important questions regarding its independence from other positive followerfocused leadership types, such as transformational, authentic, and ethical leadership which have, to date, been the focus of voice research (e.g., Detert \& Burris, 2007; Hsiung, 2012; Walumbwa \& Schaubroeck, 2009). Yet empirical work consistently confirms this independence, with 
research suggesting that servant leadership may explain between 5\% and 28\% more variance in a broad range of work outcomes, including organisational citizenship behaviour (Hoch et al., 2016), than these other leadership types (Sendjaya et al., 2017; Hoch, Bommer, Dulebohn, \& $\mathrm{Wu}, 2016)$. It is servant leadership's unique focus on serving follower needs that is its defining quality (Chiniara \& Bentein, 2016; Liden et al., 2014), and which makes salient research that explores its impact on other untested follower prosocial work behaviours, such as promotive and prohibitive voice.

Social exchange theory (Blau, 1964), and Gouldner's (1960) norms of reciprocity, are key theoretical frameworks in servant leadership research (Sendjaya \& Sorros, 2002), suggesting that follower behaviour is a reflection of their interactions and exchanges with their servant leader. Thus, a servant leader's positive treatment of their follower - putting their followers first and empowering them to perform, contribute and grow (Liden et al., 2014) - gives them the confidence and motivation to reciprocate similar behaviours. We propose, therefore, that this follower-focused and selfless servant leadership encourages employees to reciprocate with own organisation-focussed and prosocial behaviours, such as promotive and prohibitive voice (Chamberlin et al., 2017; Sendjaya \& Sarros, 2002). We propose the following hypotheses:

H1: Servant leadership is positively related to follower prohibitive (HIa) and promotive (HIb) voice.

\section{The Mediating Role of Employees' Felt Responsibility for Constructive Change}

Felt responsibility for constructive change (FRCC) is a psychological state where one feels accountable for work they are doing (Hackman \& Oldham, 1976), and is thus closely associated 
with one's work engagement and intrinsic motivation (Fuller et al., 2006). While past work recognizes both retrospective (assessing and reflecting upon past events) and prospective (envisaging future issues and concerns) forms of felt responsibility (Cummings \& Anton, 1990), FRCC research is specifically future-focussed, defining FRCC as an, "individual's belief that he or she is personally obligated to bring about constructive change" (Morrison \& Phelps, 1999, p. 407). Importantly, research has begun to establish a positive relationship between employee FRCC and voice (e.g., Fuller et al. 2006), including its promotive and prohibitive forms (Chamberlin et al., 2017). It appears that employees reporting a high FRCC are more likely to engage in both promotive and prohibitive voice.

To date, however, we could find no studies exploring the relationship between line manager servant leadership and employees' FRCC. This is surprising given the amount of research examining the importance of servant leadership for a range of related constructs such as employees' work engagement and commitment (e.g., van Dierendonck et al., 2014). LópezDomínguez, Enache, Sallan and Simo (2013), however, provide some initial evidence that servant leadership may be an important predictor of employee FRCC. Using a sample of 602 Spanish higher education employees, they report that FRCC mediates the positive relationship between employees' perceptions of developmental leadership (an individualised consideration dimension of transformational leadership) and their change orientated organisational citizenship behaviour. Our research extends this limited body of work, focussing more specifically on the role of FRCC in the relationship between servant leadership and employees' promotive and prohibitive voice, and within a new cross sector KSA context.

Thus, in line with social exchange theory (Blau, 1964) we argue that servant leadership through its focus on followers first and empowering followers to act (Liden et al., 2008) - 
promotes greater follower voice because it stimulates a FRCC. Put differently, follower willingness to reciprocate the other-focussed behaviour of their servant leader, through their own promotive and prohibitive voice, stems from the intrinsic motivation and felt responsibility for organisational improvement stimulated by their line manager. We propose the following hypotheses:

H2: Employees' felt responsibility for constructive change is positively related to their prohibitive and promotive voice and mediates the positive relationship between servant leadership and follower prohibitive $(\mathrm{H} 2 \mathrm{2})$ and promotive $(\mathrm{H} 2 \mathrm{~b})$ voice.

\section{The Moderating Role of Employees' Avoidance and Approach Orientation}

Research exploring boundary conditions of the effects of servant leadership are in their infancy (van Dierendonck, 2011), and have tended to focus on potential climate moderators, such as ethical climate (Jaramillio, Grisaffe, Chonko, and Roberts, 2009) and team climate for innovation (Yoshida, Sendjaya, Hirst, \& Cooper, 2014). A recent study by Newman, Schwarz, Cooper, and Sendjaya (2017) has, however, begun to extend this stream of servant leadership research to include follower individual differences as potential moderators. In a survey of 466 supervisor-subordinate dyads in a Chinese state-owned enterprise, Newman et al. (2017) reported that employee perceptions of leader-member exchange mediates a positive relationship between servant leadership and their organisational citizenship behaviour, and this relationship is stronger for those with a high proactive personality. We thus meet the call of Newman et al. (2017) for more servant leadership research exploring the role of individual differences in moderating its effects on employee prosocial behaviour, introducing employee dispositional 
avoidance-approach motivation as a new follower-focussed moderator of the servant leadership FRCC - voice behaviour relationship.

Drawing upon seminal psychological studies into human 'pleasure-or-pain' responses (Elliot \& Covington, 2001), avoidance-approach motivations are broad mental models for goal pursuit and achievement (McClelland, Atkinson, Clark, \& Lowell, 1953), where approach motivated individuals are predisposed to improve their circumstances at work by, "seeking out new opportunities for demonstrating success" (Kakkar et al., 2016, p. 1342). Approach motivated individuals are thus more proactive in seeking out opportunities to exhibit their contributions, including the voicing of new ideas (e.g., Elliot \& Harackiewicz, 1996). Avoidance motivated individuals, alternatively, are predisposed to, "reduce harm to themselves by monitoring possible threats in the environment" (p. 1342). Avoidance motivated individuals are, therefore, less focussed on generating new ideas (Cacioppo, Priester, \&Bernston, 1993), and more attuned to expressing their concerns regarding current and future threats to the organisation (Lin \& Johnson, 2015; Morrison \& Rothman, 2009).

We, therefore, extend existing servant leadership research that has tended to draw on social exchange theory (Blau, 1964), introducing role theory (Katz \& Kahn, 1978) to examine the differential moderating effects of follower approach-avoidance motivation on the indirect relationship between servant leadership and their prohibitive and promotive voice. Role theory suggests that a combination of dispositional, role, and contextual factors influence whether and how individuals engage in workplace behaviours, such as voice (Ilgen \& Hollenbeck, 1991). While early approach-avoidance motivation research suggests that approach orientated individuals are greater risk takers than the avoidance-orientated, and thus more likely to engage in risky voice behaviour (Friedman \& Förster, 2001), more recent research suggests that both 
approach and avoidance orientated individuals take risks, it is just that the nature of this behaviour may be different (Kakkar et al., 2016).

In turn, therefore, both high approach and high avoidance motivated employees are change-orientated, it is just that the focus and behavioural manifestation of this change orientation is different. For the high avoidance motivated, change is enacted through the identification of harmful organisational norms, practices and behaviours. For the approach motivated, change is enacted through their proactive improvement of organisational norms, practices and behaviours. Thus, we propose that the positive relationship between servant leadership and employee FRCC will be significantly weaker for those who are both high in avoidance or approach motivation. In other words, high approach or high avoidance orientated individuals are already predisposed to changing their environment, and thus the role servant leaders are required to play in stimulating a FRCC is lessened. We proposed the following hypotheses:

H3: The positive relationship between servant leadership and employees' felt responsibility for constructive change will be weakened for both high avoidance motivated employees $(\mathrm{H} 3 \mathrm{a})$ and high approach motivated employees $(H 3 b)$.

In turn, we propose employee avoidance-approach motivation has differential 'knock on’ effects for their prohibitive and promotive voice, respectively. Kakkar et al. (2016) define approach-avoidance motivation as performance-prove (approach) and performance-avoid (avoidance) goal orientations (see also, Elliot \& Harackiewicz, 1996). They suggest that approach orientated employees are more likely attuned to opportunities for demonstrating their 
success, and that this disposition is likely to align more with an enactment of promotive voice. Conversely, they argue that avoidance orientated employees are more attuned to risks and threats in the environment and that this disposition is likely to align more with the identification of performance failures associated with prohibitive voice (Kakkar et al., 2016). These arguments parallel recent research exploring the differential ties of promotion and prevention foci on individuals' promotive and prohibitive voice behaviours respectively (Lin \& Johnson, 2015), where a promotion focus emphasizes the setting of idealized goals and is associated with positive emotions such as excitement that are more likely to be expressed through promotive voice. A prevention focus, on the other hand, emphasizes vigilance and is associated with negative emotions such as anxiety and fearfulness, and is more likely to be expressed through prohibitive voice (Lin \& Johnson, 2015).

We argue, therefore, that the indirect effect of servant leadership on employee prohibitive voice - via their FRCC - will be weakened for those high avoidance orientated. High avoidance orientated individuals are already predisposed to engage in prohibitive voice behaviours (Kakkar et al., 206) and thus the role of servant leaders in promoting greater prohibitive voice is thus diminished. Conversely, we also argue that the indirect effect of servant leadership on employee promotive voice - via their FRCC - will be weakened for those high approach orientated. High approach orientated individuals are already predisposed to engage in promotive voice behaviours (Kakkar et al., 2016) and thus the role of servant leaders in promoting greater promotive voice is thus diminished. The following hypotheses are proposed: 
H4a: Follower felt responsibility for constructive change is positively related to their prohibitive voice and mediates the positive relationship between servant leadership and follower prohibitive voice, but these indirect relationships are weakened for high avoidance motivated employees. H4b: Follower felt responsibility for constructive change is positively related to their promotive voice and mediates the positive relationship between servant leadership and follower promotive voice, but these indirect relationships are weakened for high approach motivated employees.

Figure 1, below, provides a summary of our hypothesized model. The following sections describe our methodology, present our main findings and discuss their implications for theory, future research and practitioners.

\section{INSERT FIGURE 1 HERE}

\section{METHODS}

Using convenience sampling and supervisor-supervisee dyads, data were collected using hard copies of two different questionnaires - one for the supervisor and one for his/her supervisee. The supervisor's questionnaire consisted of the measures of their supervisees' promotive and prohibitive voice. The supervisees' questionnaire consisted of the measures of servant leadership, FRCC, and approach-avoidance orientation. The two questionnaires were coded so that they could be later 'matched' and, we believe, they provided the best assessment of each variable and reduced the threat of self-report biases (Podsakoff, MacKenzie, \& Podsakoff, 2012).

Business undergraduate students distributed 350 supervisor-supervisee questionnaires to 46 public and private organizations from the education, health-care, service, hospitality, and 
manufacturing sectors. These organizations operate in one or more of the three big cities of the Kingdom of Saudi Arabia (KSA) - Riyadh, Jeddah, and Dammam. We first contacted and recruited supervisees who confirmed their main supervisor. Once recruited, we approached the named supervisor and asked them to complete a survey that rated their named supervisees' promotive and prohibitive voice behaviour. Once both questionnaires were completed, we used the codes to pair them. Most supervisors were first-line managers, as it was difficult for us to approach middle or top-level managers due their busy schedules.

A total of 268 paired questionnaires were received. However, after discarding 37 cases with missing data, 231 completed matched dyads (200 supervisors and 231 supervisees) remained; giving a usable response rate of $66 \%$. Names of the respondents were deleted during the data entry process to ensure anonymity. Among the participating supervisees, $65 \%$ were men and $35 \%$ were women, $67 \%$ were Saudi nationals and $33 \%$ were expatriates, $87 \%$ had an undergraduate degree or higher, and their average age and tenure were 30.7 and 5.4 years respectively. Among the participating supervisors, $70 \%$ were men and 30\% were women, 58\% were Saudi nationals and $42 \%$ were expatriates, their average age was 39.7 , and the average time they were supervising the reported supervisee(s) was 4.57 years.

\section{Measures}

Unless stated otherwise, all questions were measured on a Likert scale ranging from 1 (not at all) to 5 (to a great extent).

Servant leadership was measured using Liden et al. (2014)'s 7-item shorter version of Liden et al. (2008)'s 28-item servant leadership scale. A sample item is "My supervisor puts my 
best interests ahead of his/her own." A Cronbach alpha score of .85 provides good support for the reliability of this scale.

Felt responsibility for constructive change was measured by a 5 -item scale developed by Morrison \& Phelps (1999). This scale was further validated by Fuller et al. (2006). A sample item is "I feel a personal sense of responsibility to bring about change at work." A Cronbach alpha score of .88 provides good support for the reliability of this scale.

Approach motivation and avoidance motivation were measured by using the four-item approach and avoidance orientation scales developed by VandeWalle (1997). Sample items of approach orientation and avoidance orientation are "I prefer to work on projects where I can prove my ability to others" and, "I prefer to avoid situations at work where I might perform poorly" respectively. Cronbach alpha scores of .73 and .88 for employees' approach and avoidance orientation respectively, provide good support for the reliability of these scales.

Promotive and prohibitive voice were measured by using the five-item scales for each developed by Liang et al. (2012). Sample items of promotive and prohibitive voice are, "He/she makes constructive suggestions to improve the unit's operation" and, "He/she advises other colleagues against undesirable behaviors that would hamper job performance" respectively. A Cronbach alpha score of .85 for both promotive and prohibitive voice, provides good support for the reliability of these scales.

Control variables. Supervisee gender, age, nationality (Saudi national or non-Saudi), work experience, and relationship tenure with current supervisor (i.e., since how long he/she has been reporting to that supervisor) were used as control variables due to their likely effect on proactive voice (Liang et al., 2012; Morrison, 2014; Van Dyne \& LePine, 1998). We also controlled for followers' (internalized) moral identity, where moral identity refers to an 
individual's moral traits-based self-schema that serves as a reference to guide the individual about his/her own and others normative behaviour (Aquino \& Reed II, 2002).

Moral identity has been shown to influence employee prosocial behaviours. Aquino et al., (2009), across 4 experimental studies, reports that those with a higher moral identity are likely to report more cooperative and less self-interested attitudes and behaviours, including contributing to wider public good (see also, Arain, 2017). While not specifically focussing on our core concepts of felt responsibility for constructive change and prosocial voice, these both tap into similar attitudes and behaviours focussed on the organizational greater good. We suggest, therefore, that one's moral identity would similarly positively influence an employee's motivation to enact change (FRCC) and prosocial voice. We measured moral identity using the 5-item scale of Aquino and Reed II (2002). A sample item of this scale is "It would make me feel good to be a person who has these characteristics." The Cronbach alpha of this scale for our study was .85 .

\section{RESULTS}

All analysis was carried out using the structural equation modelling software AMOS version 23 (Arbuckle, 2014). In line with convention, we used a combination of fit indices - chi-square $\left(\chi^{2}\right)$ and degrees of freedom (df), Comparative Fit Index (CFI), Tucker-Lewis Index (TLI) and the Root Mean Square Error of Approximation (RMSEA) - to assess the adequacy of our models and compared our hypothesized models with reasonable alternative measurement models (Bentler \& Bonnett, 1980). CFI and TLI scores above .90 and RMSEA scores below .70 are judged to confirm a good model fit (Hair, Black, Babin, \& Anderson, 2010). 


\section{Confirmatory Factor Analysis (CFA)}

Before progressing to our main hypothesis testing, we carried out CFA on the main model variables to confirm their independence. We tested five alternative models. Model 1 is our hypothesized 6-factor model, where items for servant leadership, FRCC, approach orientation, avoidance orientation, promotive voice and prohibitive voice are loaded onto six separate factors. Model 2 is a 5-factor model where items for promotive and prohibitive voice are combined into a single factor, and all other items are loaded onto their separate factors. Promotive and prohibitive voice are both prosocial voice behaviours and, as such, confirming their independence was deemed essential before we progressed. Model 3 is an alternative 5 -factor model where items for approach and avoidance orientation are combined into a single factor, and all other items are loaded onto their separate factors. Again, approach and avoidance motivation are both goal motivations and one would expect a close conceptual overlap. Confirming their independence was again seen as particularly important before proceeding with our main model testing. Model 4 is a 4-factor model where items of promotive and prohibitive voice are loaded onto a single factor and items for avoidance and approach orientation are loaded onto a single factor. All other items are loaded onto their separate factors. Finally, we tested a 1-factor solution where all items for all scales are loaded onto a single factor. In our various 6-factor, 5-factor and 4-factor models, we expected the latent variables to correlate and these covariances were included in the CFA models. 
Table 1 confirms that our hypothesized model (Model 1) is an acceptable fit with the data $(\mathrm{CFI}=.91, \mathrm{TLI}=.89$, and RMSEA $=.06)$. All alternative models reported poorer fit statistics, and our tests of comparative chi-square confirm our hypothesized model is a significantly better fit with the data than all other models. Given these results, and the excellent Cronbach alpha reliability scores across all our measurement scales (reported in italics in Table 2), we proceeded with confidence with our analysis.

\section{Descriptive Statistics}

We first computed, using SPSS version 25 (IBM Corp, 2017), the means, standard deviations and inter-correlations of our control and model variables (see Table 2). As expected, the majority of our main model variables are correlated, and in the direction predicted. These significant relationships gave us the confidence to proceed with our hypotheses testing. While avoidance orientation is not correlated significantly with servant leadership, FRCC, promotive voice, or prohibitive voice, it was retained as its potential role as a moderator of other relationships was central to our hypothesized model. An examination of the correlation matrix also highlights that employee nationality and moral identity were the only control variables significantly related to any of the mediator or dependent variables. Consequently, we retained these two controls for the main model testing ${ }^{1}$.

\footnotetext{
${ }^{1}$ Path analysis was also run without any controls and all findings held.
} 


\section{Hypothesis Testing: Mediation (H1 and H2)}

In order to control for potential common method bias, or unmeasured effects (James \& Brett, 1984), in our moderated-mediation model, we followed the recommendations of Shaver (2005) and correlated the error terms between our mediator and two dependent variables in our path analysis model. Table 3 provides a summary of the path estimates for our hypothesised model. As predicted, servant leadership is positively associated with employee FRCC $(\mathrm{B}=.34, p=.000)$. Moreover, employees' FRCC is positively related to their prohibitive voice $(\mathrm{B}=.86, p=.000)$ and mediates the positive relationship between servant leadership and employee prohibitive voice $(\gamma$ $=.25, p=.002)$. Hypotheses $1 \mathrm{a}$ and $2 \mathrm{a}$ are thus confirmed. The non-significant main effect between servant leadership and employee prohibitive voice $(\mathrm{B}=.04, p=.766)$ suggests full mediation. Against predictions, employees' FRCC was not significantly related to their promotive voice $(\mathrm{B}=-.19, p=.232)$ and thus did not mediate the relationship between servant leadership and employee promotive voice $(\beta=-.07, p=.250)$. Hypothesis $2 \mathrm{a}$ and $2 \mathrm{~b}$ are thus rejected. A significant main effect between servant leadership and employee promotive voice was observed, however $(\mathrm{B}=.37, p=.000)$.

It appears that employee perceptions of their line manager as a servant leader are strongly associated with their FRCC. Moreover, this FRCC has differential effects on their prohibitive and promotive voice behaviour. More specifically, our findings suggest that an employee's FRCC is a key precursor of the, more risky, prohibitive voice behaviour, but not of their promotive voice. 


\section{Hypothesis Testing: Moderation (H3)}

As hypothesized, employee avoidance orientation moderates the relationship between their perceptions of servant leadership and their FRCC ( $\mathrm{B}=-.15, p=.001)$. Figure 2 confirms the hypothesised direction of this moderation effect, with the positive relationship between servant leadership and employees' FRCC significantly weaker when employees report a high avoidance motivation. Hypothesis 3a is thus supported. Against expectations, employee approach motivation did not moderate the relationship between servant leadership and employee FRCC $(\mathrm{B}=.09, p=.085)$. Hypothesis $3 \mathrm{~b}$ is rejected, therefore. It appears that avoidance motivation, and not approach motivation, may be a significant boundary condition on the positive relationship between servant leadership and employee FRCC.

\section{Hypothesis Testing: Moderated-Mediation (H4)}

As predicted, employee FRCC is positively related to their prohibitive voice $(\mathrm{B}=.86, p=.000)$ and mediates the positive relationship between servant leadership and their prohibitive voice $(\beta=$ $.25, p=.002)$, but this indirect effect is significantly weaker for those reporting a high avoidance motivation ( $\beta=-.12, p=.009)$. As hypothesised, it appears that the role servant leaders have in promoting greater employee FRCC and, in turn, prohibitive voice behaviours are significantly weakened for those reporting a high avoidance motivation. Hypothesis $4 \mathrm{a}$ is thus supported. Against expectations, employee approach motivation did not strengthen the indirect effect of servant leadership on employee promotive voice $(\beta=-.02, p=.202)$. Hypothesis $4 \mathrm{~b}$ is thus rejected. 


\section{Fit Statistics and the Final Model}

We again used a combination of chi-square and degrees of freedom $(\chi 2(\mathrm{df}))$, CFI, TLI and the RMSEA to assess the adequacy of our hypothesised model (Bentler \& Bonnett, 1980). Our model is a poor fit with the data $\left(\chi^{2}(\mathrm{df})=74.88(26), p=.00, \mathrm{CFI}=.84\right.$, TLI $=.73, \mathrm{RMSEA}=$ .09). We tested, therefore, an alternative model that did not include the non-significant approach orientation x servant leadership interaction paths, although approach motivation was retained as a control variable. This more parsimonious model is an excellent fit with the data $\left(\chi^{2}(\mathrm{df})=\right.$ 21.38(17), $\mathrm{p}=.21, \mathrm{CFI}=.98, \mathrm{TLI}=.97, \mathrm{RMSEA}=.03)$, and Figure 3 highlights the adjusted path estimates for this model.

\section{------ INSERT FIGURE3 HERE ------}

\section{DISCUSSION}

We found good, albeit partial, support for our model. Employees' FRCC was found to be positively related to their prohibitive voice and fully mediated the positive relationship between servant leadership and their prohibitive voice. Moreover, these effects were significantly weaker for those employees reporting a high avoidance motivation. When employees view their line managers as servant leaders, it appears they are more likely to develop a FRCC and, in turn, engage in more prohibitive voice, but only when they report low avoidance motivation. It seems that the high avoidance motivated individual's predisposition for change and prohibitive voice behaviour (Kakkar et al., 2016), makes less salient the role of servant leaders in engendering greater FRCC and, in turn, prohibitive voice. While we did not find equivalent strengthening effects of high approach motivation on the indirect relationship between servant leadership and 
employee promotive voice, we still propose a number of important empirical and theoretical implications of our research.

First, the voice literatures are provided with new empirical support for the differential antecedents of promotive and prohibitive voice (e.g., Wei, Zhang \& Chen, 2015). Meeting the recent call from Chamberlin et al., (2017), we provide initial evidence that employee FRCC is a significant predictor of employee prohibitive voice but not their promotive voice. Prohibitive voice is a particularly risky form of prosocial voice and our findings suggest that servant leadership may encourage prohibitive voice because servant leaders instil a sense of FRCC.

Second, we extend recent research into the differential relationships between employee approach-avoidance motivation and their promotive and prohibitive voice (Kakkar et al., 2016; Lin \& Johnson, 2015). Elliot \& Harackiewicz (1996) suggest that avoidance orientated employees are more attuned to risks and threats in the environment and that this disposition is more likely to align with the identification of performance failures associated with prohibitive voice (Kakkar et al., 2016). In short, high avoidance-orientated employees are more likely to engage in prohibitive, rather than promotive, voice. Our findings partially support these propositions, as we observed the influence of servant leadership and FRCC for employee prohibitive voice weakening for those already predisposed to engage in prohibitive voice behaviour.

Third, we provide the servant leadership and voice literatures with a new theoretical framework for understanding how, when and why servant leadership influences employee voice behaviours. Specifically, we extend previous servant leadership and voice research that has leaned heavily on social exchange theory (e.g. Mayer, 2010; van Dierendonck et al., 2014), and draw on role theory to present a more complex lens for exploring, and understanding, the 
relationship between servant leadership and follow promotive and prohibitive voice. In turn, we also add to recent work that seeks to understand how different followers may respond differently to servant leadership (Antonakis, Day, \& Schyns, 2012; Newman et al., 2017; van Direndonck, 2011; Yoshida et al., 2014). Of course, much more work is needed to replicate our findings and build a more solid empirical base for our model.

\section{Limitations and Future Research Directions}

Our findings must be judged in light of some methodological limitations that are presented here as opportunities for future research. The results of our study are drawn from cross-sectional data and thus the causal relationships proposed in our model cannot be fully tested. This said, there is a logic to our proposed model which is aligned with our social exchange theory framework and with the findings of past associated leadership and servant leadership research that has better tested causality (Neubert et al., 2008). Despite this, we echo van Dierendonck's (2011) call for longitudinal research that replicates the findings of our study.

Despite, collecting our dependent variable data from an alternative source (line manager) to all other variables (employee), we recognize that our independent, moderator and mediator variables were collected from the same source (employee). While the dispositional and attitudinal nature of these variables made salient the employee as respondent, we are aware that the analysis of these variables is open to common method problems (Podsakoff et al., 2012). This said, it is commonly felt that concerns of common method bias may be reduced within moderated regression such as ours, with common source data more likely to limit the observation of significant interaction effects (e.g., Siemsen et al., 2011). The statistically significant interaction between servant leadership and avoidance orientation on employees FRCC, is 
evidence, therefore, that common method bias may not be a major problem in our study (McClelland \& Judd, 1993). Moreover, we followed the recommendations of Shaver (2005) for overcoming the problems of common method bias in mediation models such as ours and correlated the error terms between our mediator and two dependent variables in our path analysis model. Despite these observations, we still request future research that seeks objective and multisource data to further reduce the problems associate with same source bias.

We also recognise the potential nested nature of our data, that is, our line manageremployee dyads are nested within 46 different organizations. Prior to our main hypothesis testing, therefore, we examined ICC1s and ICC2s, and carried out baseline multilevel modelling tests, and found no evidence for either aggregating our data to the organizational level or any additional variance explained at this higher level (e.g., Aguinis, Gottfredson, \& Culpepper, 2013; Shrout \& Fleiss, 1979; Klein et al., 2000).

Our research was also carried out in the Kingdom of Saudi Arabia and, as a result, the generalizability of our findings to other national contexts that differ in terms of their institutional and/or cultural norms is limited. Again, however, prior research in the fields of servant leadership, FRCC and voice have tended to proliferate in other contexts, in particular, the USA, Europe and China and, as a result, there is growing evidence of the transferability of these constructs and social exchange theory to different national and cultural contexts (van Dierendonck, 2011). This said, we again call for future research that replicates our findings to those national and cultural contexts that are different from the Kingdom of Saudi Arabia.

In addition to these method limitations, we also propose one or two additional avenues of enquiry. First, while we tentatively explored the differential effects of employees' avoidance/approach orientation on their promotive and prohibitive voice (see Kakkar et al., 
2016; Lin \& Johnson, 2015) - and found no support for this in our model - we also recognize the potential salience of an alternative model - where employees' avoidance/approach orientation differentially moderates the path between their FRCC and their promotive and prohibitive voice. Specifically, that avoidance orientation may be a more important positive moderator of the relationship between FRCC and prohibitive voice and approach orientation the relationship between FRCC and promotive voice (see Kakkar et al., 2016; Lin \& Johnson, 2015). This alternative model was tested post hoc, and not supported in our data set. However, we do recognize this emerging body of research and request more work exploring the potential differential moderating effects of employees' approach/avoidance orientation on their promotive and prohibitive voice behaviours.

Finally, we also call for more research that examines different individual dispositional moderators of servant leadership. For instance, there appears to be evidence that individual's power distance orientation (Morrison, 2014) or proactive personality (Newman et al., 2017) may act as a boundary condition on the direct and indirect effects of servant leadership on proactive voice. Similarly, future research might also focus on negative work behaviours. We see potentially useful work exploring whether similar effects may predict employee silence, as past research has shown silence to be an extremely powerful predictor of organizational crises and failure (Greenberg \& Edwards, 2009; Milliman et al., 2003) and future research needs to confirm whether the absence of proactive voice is the same as silence.

\section{Practical Implications}

Despite these limitations, we propose a number of important practical implications of our research. First, we provide managers and employers with a new servant leadership lens through 
which to elicit the employee proactive voice behaviours that are essential for their survival and prosperity (Liang et al., 2012). In particular, we present evidence to managers that servant leadership may help encourage employees to not only freely voice their creative ideas (promotive voice) but also encourage them to engage in the far riskier activity of highlighting current peer, team, managerial and/or operational failings (prohibitive voice). Research has shown consistently the importance of these discretionary and prosocial behaviours (e.g., Liang et al., 2012) and our research suggests managers may achieve this through their servant leadership. We encourage, therefore, employers to consider developing, promoting and recruiting line managers and supervisors who exhibit the attitudes and behaviours of a servant leader. That is, line managers who empower their followers, are sensitive to their needs and failures, and help them to grow and succeed (Liden et al., 2014; Liden et al., 2008). Interestingly, recent research exploring servant leadership development has highlighted the potential for fairly straight-forward and low-cost interventions in promoting greater servant leader behaviours (Lohrey \& Guillaume, 2015) and we encourage managers and organizations to investigate these interventions.

While our study focused on supervisors and relatively low-level line managers, we also suggest that organizations consider servant leadership qualities when recruiting and promoting individuals to senior-level management positions. It is just as important - if not more so - that employees at these higher levels are willing to take on responsibility for change and voice their suggestions and feedback as their core job roles are likely to demand these levels of engagement and creativity. As such, their senior managers' servant leadership behaviours may help to further engender these proactive and prosocial attitudes and behaviours. Of course, the appointment of servant leaders at the very top of organizations also sends a positive message to managers and employees at all levels about the core strategic importance of servant leadership and its role in 
organizations. Indeed, social learning theory (Bandura, 1986) and the trickle-down model of leadership show the pervasiveness of this informal process of communicating and transferring important leadership and organizational values throughout an organization (Liden et al., 2014).

Finally, we advise organizations and managers to consider goal motivation as an important moderator of followers' reactions to servant leadership, in particular those holding a high avoidance orientation. Goal motivations are thought to be relatively stable individual differences stemming from certain core personality traits (Elliot \& Church, 1997) and, as such, managers will find it difficult to change employees' goal motivations. Thus, in organizations, and particular roles, where employees are expected to take on responsibility for change and innovation, we suggest employers focus on selecting out those individuals who hold a high avoidance orientation. Thus, where relevant, avoidance orientation should become one additional criterion that drives employers' effective recruitment, promotion and advancement decisions into jobs that emphasize autonomy and responsibility for creativity, innovation and proactive voice.

\section{REFERENCES}

Aguinis, H., Gottfredson, R.K., \& Culpepper, S.A. (2013) Best-practice recommendations for estimating cross-level interaction effects using multilevel modeling. Journal of Management, 39(6), 1490-1528.

Antonakis, J., Day, D. V., \& Schyns, B. (2012). Leadership and individual differences: At the cusp of a renaissance. The Leadership Quarterly, 23(4), 643-650.

Aquino, K., \& Reed II, A. (2002). The self-importance of moral identity. Journal of Personality and Social Psychology, 83(6), 1423-1440. 
Aquino, K., Freeman, D., Reed, I. I., Lim, V. K., \& Felps, W. (2009). Testing a social-cognitive model of moral behavior: the interactive influence of situations and moral identity centrality. Journal of Personality and Social Psychology, 97(1), 123-141.

Arain, G. A., (2017). The impact of leadership style on moral identity and subsequent in-role performance: A moderated mediation analysis. Ethics \& Behavior. Accessed Online doi: $10.1080 / 10508422.2017 .1336622$

Arbuckle, J. L. (2014). Amos (version 23.0) [Computer Program]. Chicago: IBM SPSS.

Bai, Y., Lin, L., \& Liu, J. T. (2017). Leveraging the employee voice: a multi-level social learning perspective of ethical leadership. The International Journal of Human Resource Management. Accessed Online doi: 10.1080/09585192.2017.1308414

Bandura, A. (1986). Social Foundations of Thought and Action: A Social Cognitive Theory. Englewood Cliffs, NJ: Prentice-Hall, Inc.

Bentler, P. M., \& Bonett, D. G. (1980). Significance tests and goodness of fit in the analysis of covariance structures. Psychological Bulletin, 88(3), 588-606.

Blau, P. M. (1964). Exchange and Power in Social Life. New York, NY: Wiley.

Cacioppo, J. T., Priester, J. R., \& Berntson, G. G. (1993). Rudimentary determinants of attitudes: II. Arm flexion and extension have differential effects on attitudes. Journal of Personality and Social Psychology, 65(1), 5-17.

Chamberlin, M., Newton, D. W., \& Lepine, J. A. (2017). A Meta-Analysis of Voice and Its Promotive and Prohibitive Forms: Identification of Key Associations, Distinctions, and Future Research Directions. Personnel Psychology, 70(1), 11-71. 
Chiniara, M., \& Bentein, K. (2016). Linking servant leadership to individual performance: Differentiating the mediating role of autonomy, competence and relatedness need satisfaction. The Leadership Quarterly, 27(1), 124-141.

Cummings, L. L., \& Anton, R. J. (1990). The logical and appreciative dimensions of accountability. In S. Srivastava \& D.L. Cooperrider (Eds.) The Jossey-Bass Management Series. Appreciative Management and Leadership: The Power of Positive Thought and Action in Organizations (pp. 257-286). San Francisco, CA: Jossey-Bass.

Detert, J. R., \& Burris, E. R. (2007). Leadership behavior and employee voice: Is the door really open? Academy of Management Journal, 50(4), 869-884.

Elliot, A. J. \& Church, M. A. (1997). A hierarchical model of approach and avoidance achievement motivation. Journal of Personality and Social Psychology, 72(1), 218-232.

Elliot, A. J., \& Covington, M. V. (2001). Approach and avoidance motivation. Educational Psychology Review, 13(2), 73-92.

Elliot, A. J., \& Harackiewicz, J. M. (1996). Approach and avoidance achievement goals and intrinsic motivation: A mediational analysis. Journal of Personality and Social Psychology, 70(3), 461-475.

Ferris, D. L., Johnson, R. E., Rosen, C. C., Djurdjevic, E., Chang, C.-H. D., \& Tan, J. A. (2013). When is success not satisfying? Integrating regulatory focus and approach/avoidance motivation theories to explain the relation between core self-evaluation and job satisfaction. Journal of Applied Psychology, 98(2), 342-353.

Ferris, D. L., Rosen, C. R., Johnson, R. E., Brown, D. J., Risavy, S. D., \& Heller, D. (2011). Approach or avoidance (or both?): Integrating core self-evaluations within an approach/avoidance framework. Personnel Psychology, 64(1), 137-161. 
Friedman, R. S., \& Förster, J. (2001). The effects of promotion and prevention cues oncreativity. Journal of Personality and Social Psychology, 81(6), 1001-1013.

Fuller, J. B., Marler, L. E., \& Hester, K. (2006). Promoting felt responsibility for constructive change and proactive behavior: Exploring aspects of an elaborated model of work design. Journal of Organizational Behavior, 27(8), 1089-1120.

Gouldner, A. W. (1960). The norm of reciprocity: a preliminary statement. American Sociological Review, 25(2), 161-178.

Graham, G. L. (2002). If you want honesty, break some rules. Harvard Business Review, 80(4), $42-47$.

Greenberg, J., \& Edwards, M. S. (Eds.) (2009). Voice and Silence in Organizations. Bingley, UK: Emerald Group Publishing.

Hackman, J. R., \& Oldham, G. R. (1976). Motivation through the design of work: Test of a theory. Organizational Behavior and Human Performance, 16(2), 250-279.

Hair, J. F., Black, W. C., Babin, B. J., \& Anderson, R. E. (2010). Multivariate Data Analysis (7th ed.). Upper Saddle River, NJ: Prentice Hall.

Hirschman, A. O. (1970). Exit, Voice, and Loyalty: Responses to Decline in Firms, Organizations, and States. Cambridge, MASS: Harvard University Press.

Hoch, J. E., Bommer, W. H., Dulebohn, J. H., \& Wu, D. (2018). Do Ethical, Authentic, and Servant Leadership Explain Variance Above and Beyond Transformational Leadership? A Meta-Analysis. Journal of Management, 44(2), 501-529.

Hsiung, H.-H. (2012). Authentic leadership and employee voice behavior: A multi-level psychological process. Journal of Business Ethics, 107(3), 349-361. 
Hu, D., Zhang, B., \& Wang, M. (2015). A Study on the Relationship among Transformational Leadership, Organizational Identification and Voice Behavior. Journal of Service Science and Management, 8(1), 142-148.

IBM Corp. (2017). SPSS Statistics for Windows, Version 25.0. Armonk, NY: IBM Corp.

Ilgen, D. R., \& Hollenbeck, J. R. (1991). Job design and roles. Handbook of Industrial and Organizational Psychology, 2, 165-207.

James, L.R., \& Brett, J.M. (1984). Mediators, moderators, and tests for mediation. Journal of Applied Psychology, 69, 307-321.

Jaramillo, F., Grisaffe, D. B., Chonko, L. B., \& Roberts, J. A. (2009). Examining the impact of servant leadership on sales force performance. Journal of Personal Selling \& Sales Management, 29(3), 257-275.

Kakkar, H., Tangirala, S., Srivastava, N. K., \& Kamdar, D. (2016). The dispositional antecedents of promotive and prohibitive voice. Journal of Applied Psychology, 101(9), 1342-1351.

Katz, D., \& Kahn, R. L. (1978). The Social Psychology of Organizations (2 ${ }^{\text {nd }}$ Edition). New York, NY: Wiley.

Klein, K. J., Bliese, P. D., Kozolowski, S. W. J., Dansereau, F., Gavin, M. B., \& Griffin, M. A. et al (2000). Multilevel analytical techniques: Commonalities, differences, and continuing questions. In K. J. Klein \& Kozlowski, S. W. J. (Eds.), Multilevel theory, research, and methods in organizations: Foundations, extensions, and new directions (pp. 512-553). San Francisco, CA Jossey-Bass.

Kong, F., Huang, Y., Liu, P., \& Zhao, X. (2016). Why Voice Behavior? An integrative model of the need for affiliation, the quality of leader-member exchange, and group cohesion in predicting voice behavior. Group \& Organization Management, 42(6), 792-818. 
LePine, J. A., \& Van Dyne, L. (1998). Predicting voice behavior in work groups. Journal of Applied Psychology, 83(6), 853-868.

Li, A. N., Liao, H., Tangirala, S., \& Firth, B. M. (2017). The Content of the Message Matters: The Differential Effects of Promotive and Prohibitive Team Voice on Team Productivity and Safety Performance Gains. Journal of Applied Psychology, 102(8), 1259-1270.

Liang, J., Farh, C. I. C., \& Farh, J. L. (2012). Psychological Antecedents of Promotive and Prohibitive Voice: A Two-Wave Examination. Academy of Management Journal, 55(1), 71-92.

Liden, R. C., Wayne, S. J., Liao, C., \& Meuser, J. D. (2014). Servant leadership and serving culture: Influence on individual and unit performance. Academy of Management Journal, $57(5), 1434-1452$.

Liden, R. C., Wayne, S. J., Zhao, H., \& Henderson, D. (2008). Servant leadership: Development of a multidimensional measure and multi-level assessment. The Leadership Quarterly, 19(2), 161-177.

Lin, S. H. J., \& Johnson, R. E. (2015). A suggestion to improve a day keeps your depletion away: Examining promotive and prohibitive voice behaviors within a regulatory focus and ego depletion framework. Journal of Applied Psychology, 100(5), 1381.

Llopis, G. (2012). 6 reasons employees must speak up to thrive at work. Retrieved 10 March, 2018, from http://www.forbes.com/sites/glennllopis/2012/03/19/6-reasons-employeesmust-speak-up-to-thrive-at-work/

Lohrey, S., \& Guillaume, Y. R. (2015). Servant Leadership Development: The Role of Training and Leader Identification. Paper presented at the Academy of Management Proceedings. 
López-Domínguez, M., Enache, M., Sallan, J. M., \& Simo, P. (2013). Transformational leadership as an antecedent of change-oriented organizational citizenship behavior. Journal of Business Research, 66(10), 2147-2152.

Mayer, D. (2010). Servan leadership and follower need satisfaction: Where do we go from here? In D. van Dierendonck, \& K. Patterson (Eds.), Servant Leadership: Developments in Theory and Practice (pp. 147-154). Hampshire, UK: Palgrave Macmillan.

McClelland, D. C., Atkinson, J. W., Clark, R. A., \& Lowell, E. L. (1953). Century Psychology Series. The Achievement Motive. East Norwalk, CT: Appleton-Century-Crofts.

McClelland, G. H., \& Judd, C. M. (1993). Statistical difficulties of detecting interactions and moderator effects. Psychological bulletin, 114(2), 376-390.

Milliman, J., Czaplewski, A. J., \& Ferguson, J. (2003). Workplace spirituality and employee work attitudes: An exploratory empirical assessment. Journal of Organizational Change Management, 16(4), 426-447.

Morrison, E. W. (2014). Employee voice and silence. Annual Review Organizational Psychology and Organizational Behavior, 1(1), 173-197.

Morrison, E. W., \& Phelps, C. C. (1999). Taking charge at work: Extra role efforts to initiate workplace change. Academy of Management Journal, 42, 403-419.

Neubert, M. J., Kacmar, K. M., Carlson, D. S., Chonko, L. B., \& Roberts, J. A. (2008). Regulatory focus as a mediator of the influence of initiating structure and servant leadership on employee behavior. Journal of Applied Psychology, 93(6), 1220-1233.

Newman, A., Schwarz, G., Cooper, B., \& Sendjaya, S. (2017). How servant leadership influences organizational citizenship behavior: The roles of LMX, empowerment, and proactive personality. Journal of Business Ethics, 145(1), 49-62. 
Perlow, L., \& Williams, S. (2003). Is silence killing your company? Ieee Engineering Management Review, 31(4), 18-23.

Podsakoff, P. M., MacKenzie, S. B., \& Podsakoff, N. P. (2012). Sources of method bias in social science research and recommendations on how to control it. Annual Review of Psychology, 63, 539-569.

Rehg, M. T., Miceli, M. P., Near, J. P., \& Van Scotter, J. R. (2008). Antecedents and outcomes of retaliation against whistleblowers: Gender differences and power relationships. Organization Science, 19(2), 221-240.

Sendjaya, S., Eva, N., Butar Butar, I., Robin, M., \& Castles, S. (2017). SLBS-6: Validation of a Short Form of the Servant Leadership Behavior Scale. Journal of Business Ethics. Accessed Online doi: 10.1007/s10551-017-3594-3.

Sendjaya, S., \& Sarros, J. C. (2002). Servant leadership: Its origin, development, and application in organizations. Journal of Leadership \& Organizational Studies, 9(2), 57-64.

Shaver, J. M. (2005). Testing for mediating variables in management research. Concerns, implications, and alternative strategies. Journal of Management, 31(3), 330-353.

Shrout, P. E., \& Fleiss, J. L. (1979). Intraclass correlations: Uses in assessing rater reliability. Psychological Bulletin, 86, 420-428.

Siemsen, E., Roth, A., \& Oliveira, P. (2010). Common method bias in regression models with linear, quadratic, and interaction effects, Organizational Research Methods, 13, 456-476. van Dierendonck, D. (2011). Servant leadership: A review and synthesis. Journal of Management, 37(4), 1228-1261.

van Dierendonck, D., Stam, D., Boersma, P., de Windt, N., \& Alkema, J. (2014). Same difference? Exploring the differential mechanisms linking servant leadership and 
transformational leadership to follower outcomes. The Leadership Quarterly, 25, 544562.

Van Dyne, L., Cummings, L., \& Parks, J. M. (1995). Extra-role behaviors: In pursuit of construct and definitional clarity (a bridge over muddied waters). Research in Organizational Behavior, 17, 215-285.

Van Dyne, L., \& LePine, J. A. (1998). Helping and voice extra-role behaviors: Evidence of construct and predictive validity. Academy of Management Journal, 41(1), 108-119.

VandeWalle, D. (1997). Development and validation of a work domain goal orientation instrument. Educational and Psychological Measurement, 57(6), 995-1015.

Walumbwa, F. O., \& Schaubroeck, J. (2009). Leader personality traits and employee voice behavior: mediating roles of ethical leadership and work group psychological safety. Journal of Applied Psychology, 94(5), 1275-1286.

Wei, X., Zhang, Z.-X., \& Chen, X.-P. (2015). I will speak up if my voice is socially desirable: A moderated mediating process of promotive versus prohibitive voice. Journal of Applied Psychology, 100(5), 1641-1652.

Xie, X.-Y., Ling, C.-D., Mo, S.-J., \& Luan, K. (2015). Linking colleague support to employees' promotive voice: A moderated mediation model. PloS one, 10(7), e0132123.

Yoshida, D. T., Sendjaya, S., Hirst, G., \& Cooper, B. (2014). Does servant leadership foster creativity and innovation? A multi-level mediation study of identification and prototypicality. Journal of Business Research, 67(7), 1395-1404.

\section{DISCLOSURE OF INTEREST}

The authors report no conflict of interest. 


\section{FIGURE 1: HYPOTHESISED MODEL}

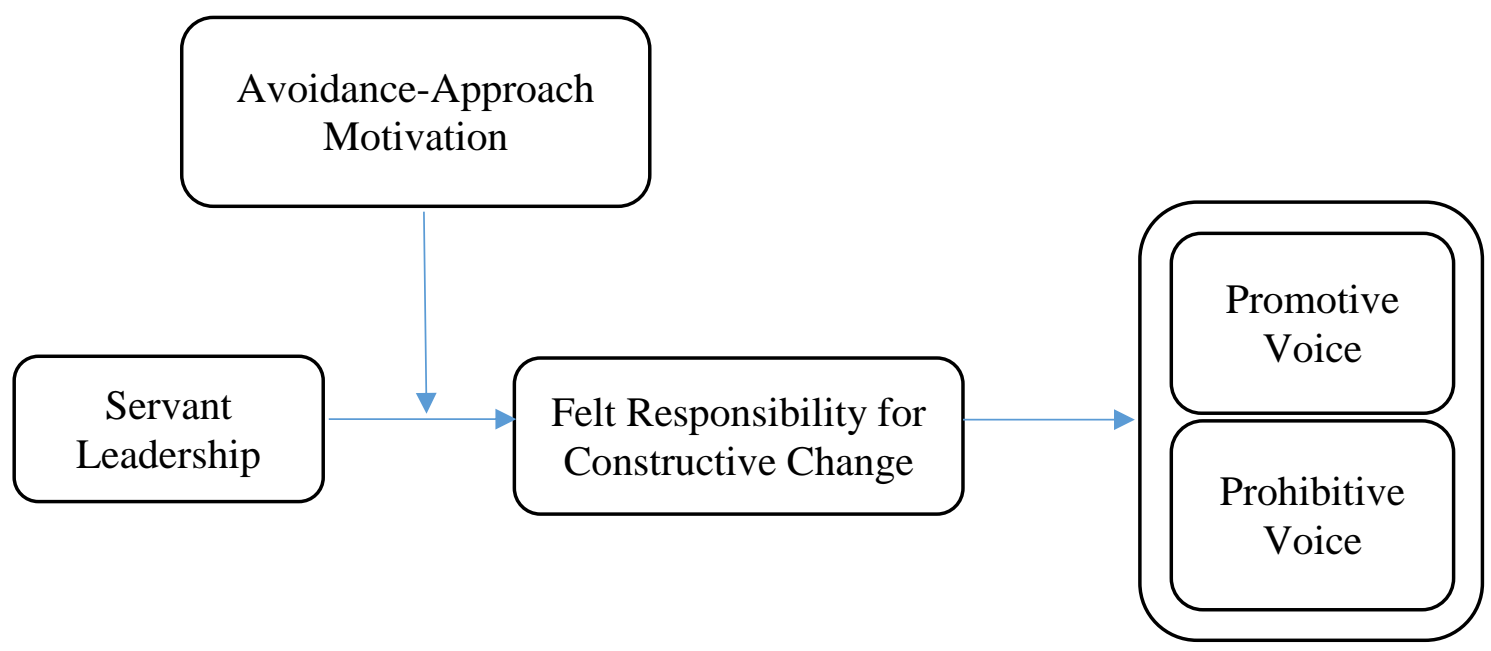


FIGURE 2: PLOTTED INTERACTION BETWEEN SERVANT LEADERSHIP AND AVOIDANCE ORIENTATION ON EMPLOYEE FRCC

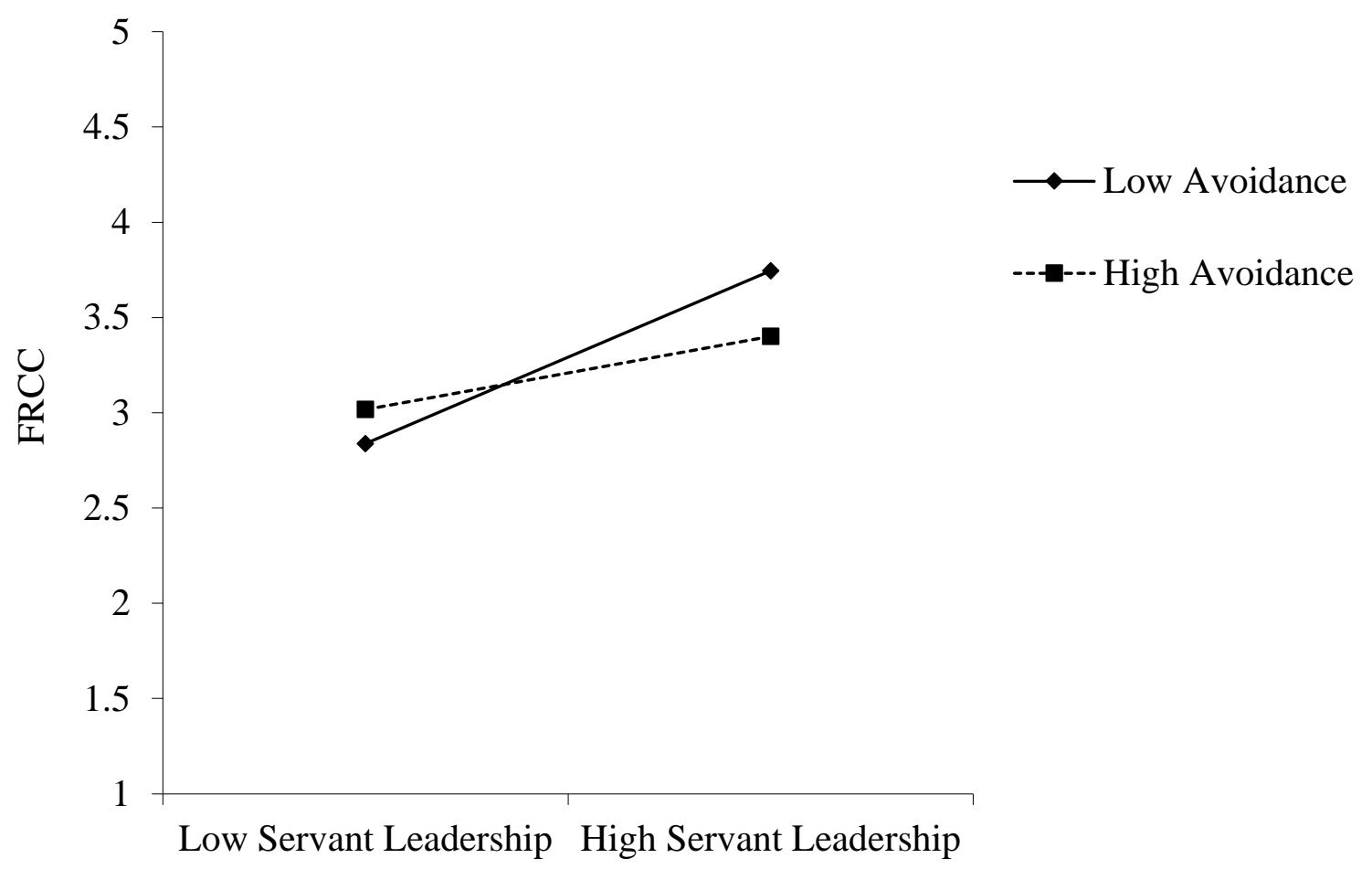

Notes: FRCC $=$ Felt responsibility for constructive change 


\section{FIGURE 3: FINAL MODEL WITHPATH ESTIMATES AND FIT STATISTICS}

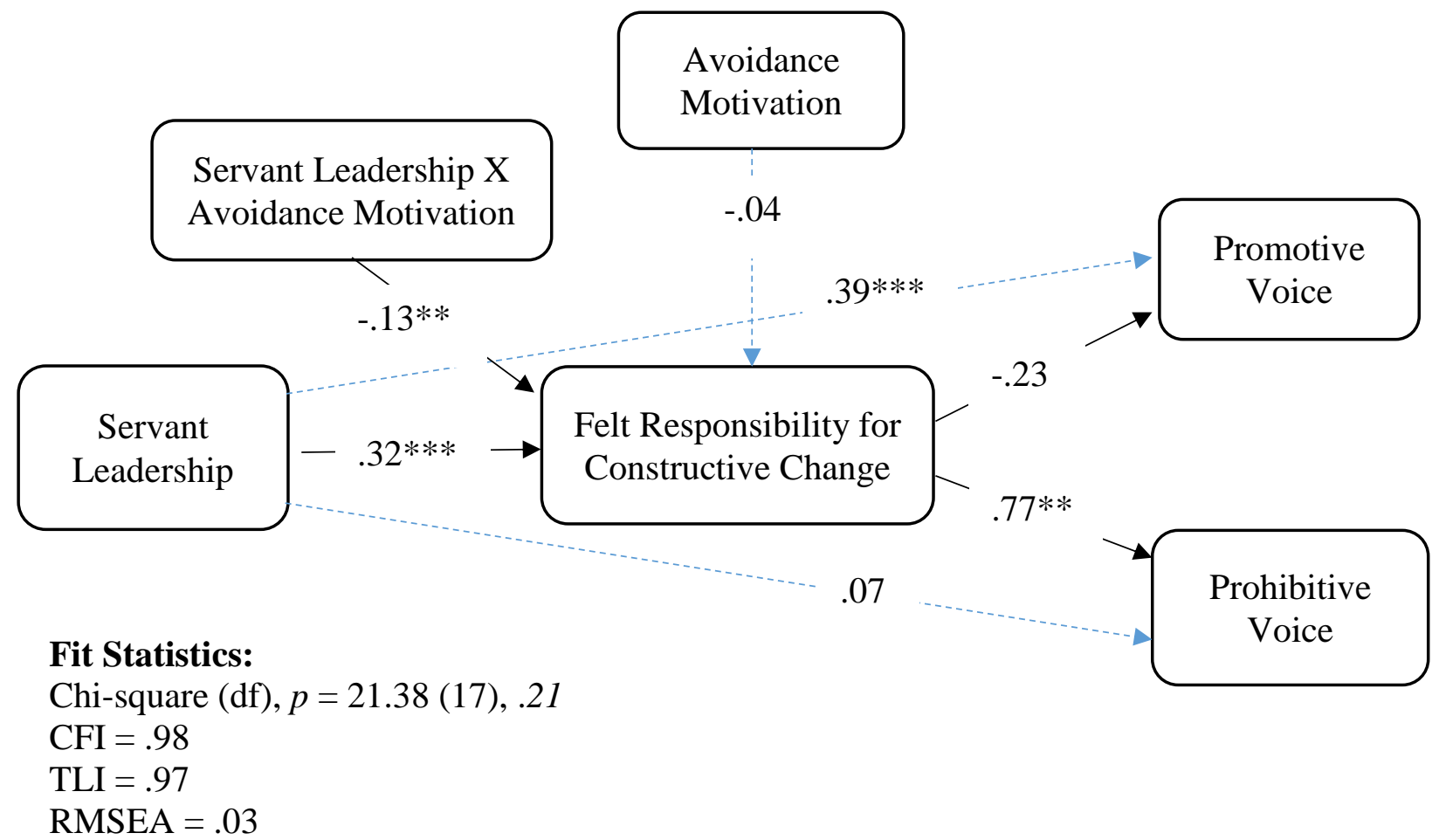

Notes: $\mathrm{N}=217 ; * * * p<.001, * * p<.01, * p<.05$;

Controls: Moral Identity, Nationality, Approach Orientation

Covaried: Moral identity and servant leadership; moral identity and avoidance orientation; moral identity and approach orientation; approach and avoidance orientation 


\section{TABLE 1: CFA Model Fit Indices and Model Fit Comparisons}

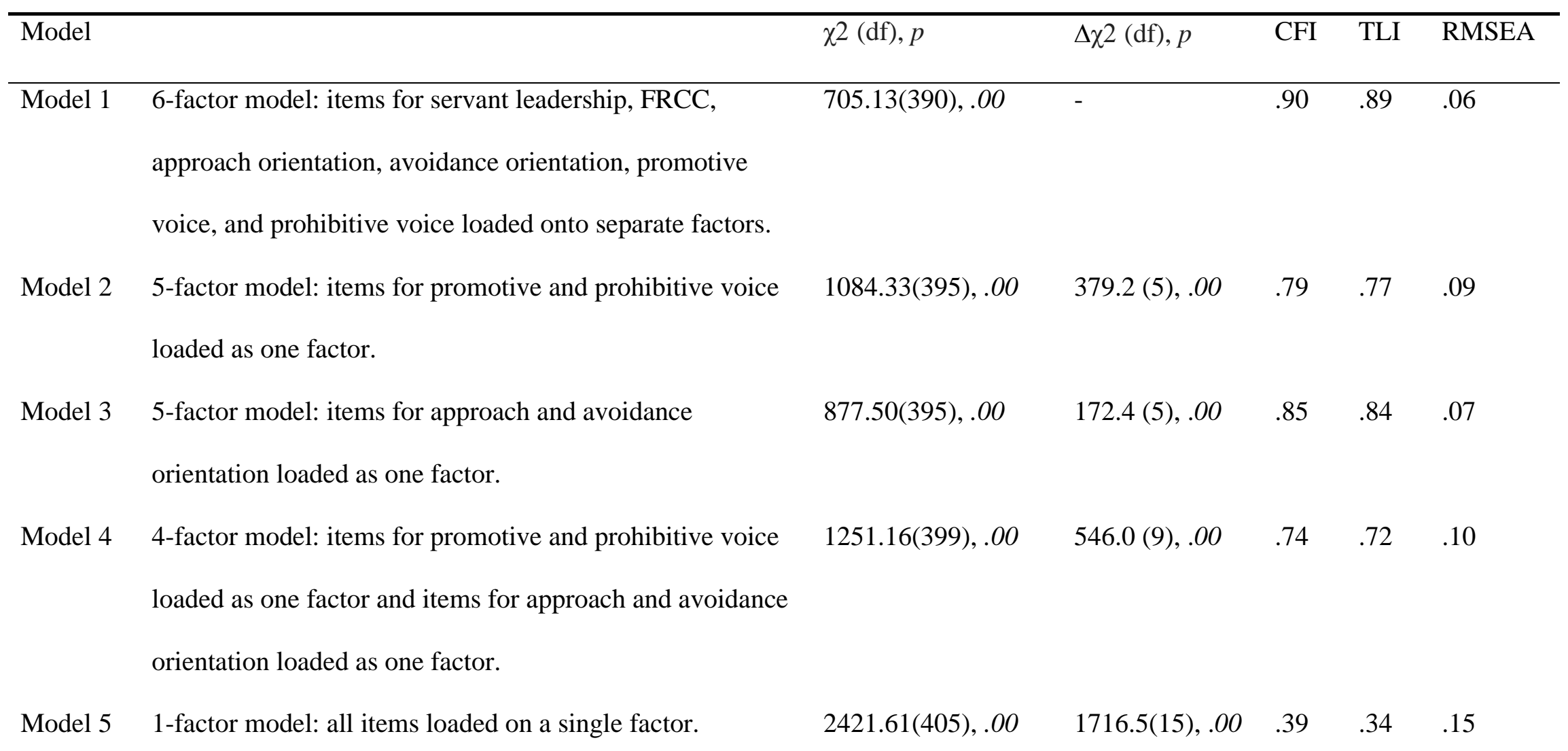

Notes. $\mathrm{N}=231$; CFI = Comparative Fit Index; TLI = Tucker Lewis Index; RMSEA = Root-Mean Square Error Approximation; $\chi 2$ (df), $p=$ chi-square (degrees of freedom) and $p$-value; $\Delta \chi 2(\mathrm{df}), p=$ difference in chi-square (degrees of freedom) and $p$-value. 
TABLE 2: MEANS, STANDARD DEVIATIONS AND INTERCORRELATIONS OF MODEL VARIABLES

\begin{tabular}{|c|c|c|c|c|c|c|c|c|c|c|c|c|c|}
\hline Variables & Mean & SD & 1 & 2 & 3 & 4 & 5 & 6 & 7 & 8 & 9 & 10 & 11 \\
\hline 1. Gender & 1.35 & .48 & & & & & & & & & & & \\
\hline 2. Age & 30.72 & 7.79 & $-.15^{*}$ & & & & & & & & & & \\
\hline 3. Education & 2.03 & .57 & .07 & .11 & & & & & & & & & \\
\hline 4. Nationality & 1.33 & .47 & $-.14 *$ & .03 & .02 & & & & & & & & \\
\hline 5. Relationship Tenure & 4.57 & 4.42 & -.13 & $.32 * *$ & .01 & .03 & & & & & & & \\
\hline 6. Approach Orient. & 3.79 & .83 & -.13 & -.11 & -.02 & .10 & .01 & & & & & & \\
\hline 7. Avoidance Orient. & 3.25 & .99 & $-.16^{*}$ & -.07 & -.01 & $.16^{*}$ & $.15^{*}$ & $.37 * *$ & & & & & \\
\hline 8. Servant Leadership & 3.78 & .75 & .02 & .03 & -.07 & .06 & -.04 & $.30 * *$ & .06 & & & & \\
\hline 9. Moral Identity & 4.23 & .65 & .06 & .09 & .06 & -.03 & -.08 & $.22 * *$ & -.03 & $.22 *$ & & & \\
\hline 10. FRCC & 3.95 & .77 & -.03 & .12 & .04 & $.21 * *$ & .09 & $.29 * *$ & .03 & $.44 * *$ & $.34 * *$ & & \\
\hline 11. Promotive Voice & 3.70 & .76 & -.02 & .05 & .08 & .09 & .06 & .06 & .01 & $.34 * *$ & $.28 * *$ & $.35^{* *}$ & \\
\hline 12. Prohibitive Voice & 3.50 & .88 & -.07 & .07 & -.02 & $.16^{*}$ & -.03 & $.20 * *$ & .02 & $.36^{* *}$ & $.26 * *$ & $.34 * *$ & $.35 * *$ \\
\hline
\end{tabular}

Notes. $\mathrm{N}=231 ;{ }^{*} p<.05,{ }^{* *} p<.01,{ }^{* * *} p<.001 ; \mathrm{FRCC}=$ Felt Responsibility for Constructive Change. 
TABLE 3: HYPOTHESISED MODEL PATH ESTIMATES

\begin{tabular}{|c|c|c|c|}
\hline Path & Estimate & S.E. & $p$ \\
\hline \multicolumn{4}{|c|}{ DV: Felt Responsibility for Constructive Change (FRCC) } \\
\hline Nationality $\rightarrow$ FRCC & .25 & .07 & .000 \\
\hline Moral Identity $\rightarrow$ FRCC & .26 & .07 & .000 \\
\hline Approach Orientation (APO) $\rightarrow$ FRCC & .15 & .06 & .001 \\
\hline Avoidance Orientation $(\mathrm{AVO}) \rightarrow$ FRCC & -.04 & .04 & .245 \\
\hline Servant Leadership (SL) $\rightarrow$ FRCC & .34 & .06 & .000 \\
\hline $\mathrm{SL} x \mathrm{AVO} \rightarrow \mathrm{FRCC}$ & -.15 & .04 & .000 \\
\hline SL $x$ APO $\rightarrow$ FRCC & .09 & .05 & .085 \\
\hline \multicolumn{4}{|l|}{ DV: Promotive Voice } \\
\hline Moral Identity $\rightarrow$ Promotive Voice & .31 & .09 & .000 \\
\hline FRCC $\rightarrow$ Promotive Voice & -.19 & .16 & .232 \\
\hline SL $\rightarrow$ Promotive Voice & .37 & .09 & .000 \\
\hline${ }^{*} S L \rightarrow$ FRCC $\rightarrow$ Promotive Voice & -.07 & & .250 \\
\hline$* S L x A P O \rightarrow F R C C \rightarrow$ Promotive Voice & -.02 & & .202 \\
\hline \multicolumn{4}{|l|}{ DV: Prohibitive Voice } \\
\hline Moral Identity $\rightarrow$ Prohibitive Voice & -.00 & .12 & .970 \\
\hline FRCC $\rightarrow$ Prohibitive Voice & .86 & .24 & .000 \\
\hline $\mathrm{SL} \rightarrow$ Prohibitive Voice & .04 & .12 & .766 \\
\hline$* S L \rightarrow F R C C \rightarrow$ Prohibitive Voice & .25 & & .002 \\
\hline$* S L \times A V O \rightarrow F R C C \rightarrow$ Prohibitive Voice & -.12 & & .009 \\
\hline
\end{tabular}

$\overline{\text { Notes: } \mathrm{N}=231 \text {; For ease of interpretation, covariances not reported; DV = Dependent variable; } * \text { Standardized indirect }}$ effects $(\beta)$ 